\title{
Identification and characteristics of saccharides from the initial soils of temperate climate and their origin and significance
}

\author{
LESZEK MARYNOWSKI ${ }^{1}$, OIMAHMAD RAHMONOV ${ }^{1}$, \\ JUSTYNA SMOLAREK-LACH ${ }^{1}$, MACIEJ RYBICKI ${ }^{1}$, \\ BERND R.T. SIMONEIT ${ }^{2}$ \\ ${ }^{1}$ Institute of Earth Sciences, Faculty of Natural Sciences, \\ University of Silesia, Bedzinska 60, Sosnowiec 41-200, \\ Poland; leszek.marynowski@us.edu.pl \\ ${ }^{2}$ Department of Chemistry, College of Science, Oregon State \\ University, Corvallis, OR 97331, USA; \\ simonebe@onid.orst.edu
}

Carbohydrates (saccharides) are most abundant class of organic compounds on Earth biosphere and the most common group of compounds that build living organisms. Their complex role includes storing energy as well as membrane and macromolecule protection against different types of stress. Saccharides are frequent constituents of lake and marine sediments, but these compounds are much more common in peat bogs, and soils. Here we present detail determination of mono- and oligosaccharides from initial soils (Arenosole) of temperate climate to observe their subsequent development connected with successive colonization of soil. Correlation between sugars, lipids and living organisms colonized soil was also provided. During the first stage of development sucrose is the most abundant saccharide in soil crust reaching up to $45000 \mu \mathrm{g} / \mathrm{g}$ TOC. Also on the second and third development stage sucrose is prevailing compound, but its concentration decreased to the range from 1600 to $16000 \mu \mathrm{g} / \mathrm{g}$ TOC. The second, and third stage of soil development characterized by a gradual increase of arabitol, mannitol and trehalose, compounds typical for fungi and lichens. Their abundances increased from several percents (comparing to major sucrose) to the range from 10 to $32 \%$ for mannitol and from 34 to $54 \%$ in the case of trehalose. Moreover, on the third development stage, such saccharides as: pinitol, myo-inositol, scyllo-inositol, arabinose together with non-sugar compounds including: dehydroabietic acid, $p$-hydroxybenzoic acid, gallic acid, and sitosterol considerably increase. All these compounds are higher plant markers, mainly derived from conifer detritus. Relationships between trehalose/ sucrose ratio vs. (mannitol + arabitol)/sucrose ratio and TOC vs. (mannitol + arabitol)/sucrose ratio excellently differentiates three stages of soil crust development. It can be used for future study of initial soils growth. 